\title{
Agentes teratogênicos e desenvolvimento fetal: Uma revisão narrativa
}

Teratogenic agents and fetal development: A narrative review

Agentes teratogénicos y desarrollo fetal: Una revisión narrative

Recebido: 01/04/2021 | Revisado: 08/04/2021 | Aceito: 12/04/2021 | Publicado: 25/04/2021

Maria Eduarda da Silva

ORCID: https://orcid.org/0000-0003-3070-4992

Universidade Federal de Pernambuco, Brasil

E-mail: me89075@gmail.com

Wellington Manoel da Silva

ORCID: https://orcid.org/0000-0002-6735-5071 Instituto de Medicina Integral Professor Fernando Figueira, Brasil

E-mail: wellington-manoel@outlook.com

Jardeson Joaquim Bezerra

ORCID: https://orcid.org/0000-0003-4449-4199 Universidade Federal do Rio Grande do Norte, Brasil

E-mail: jardesonbezerra1990@gmail.com

Joyce Neire Vidal Alexandre Souza

ORCID: https://orcid.org/0000-0003-2083-4566

Universidade de Pernambuco, Brasil

E-mail: joyceneire@hotmail.com

Robert Galvão de Souza

ORCID: https://orcid.org/0000-0001-6570-6918

Faculdade de Ciências Humanas de Olinda, Brasil

E-mail: Robert.galvao0@gmail.com

Jéssica dos Santos Costa

ORCID: https://orcid.org/0000-0003-2404-6604 Universidade Federal de Sergipe, Brasil

E-mail: jessicas_costa@outlook.com

Débora Joyce do Nascimento Camilo

ORCID: https://orcid.org/0000-0003-1841-4837

Faculdade de Ciências Humanas de Olinda, Brasil

E-mail: joycecaamilo@gmail.com

Rosivan Sebastião da Silva

ORCID: https://orcid.org/0000-0001-6271-2714

Universidade de Pernambuco, Brasil

E-mail: rosivan07@gmail.com

Nathália Monteiro da Silva

ORCID: https://orcid.org/0000-0002-2382-717X

Faculdade de Comunicação e Turismo de Olinda, Brasil

E-mail: nms.14@hotmail.com

Núbya Annyédja Marcelino da Silva

ORCID: https://orcid.org/0000-0003-1377-0824

Centro Universitário da Vitória de Santo Antão, Brasil

E-mail: nubya-luiz@hotmail.com

Bruno Santos Souza

ORCID: https://orcid.org/0000-0001-5913-5258

Faculdade AGES de Medicina, Brasil

E-mail: enfobrunosouza@gmail.com

Barbara Bispo de Santana

ORCID: https://orcid.org/0000-0002-7017-2401

Faculdade AGES de Medicina, Brasil

E-mail: barbara_bispo12@hotmail.com

Sdnei Gomes dos Santos

ORCID: https://orcid.org/0000-0002-2266-7119

Faculdade AGES de Medicina, Brasil

E-mail: sdnei.santos@ages.edu.br 


\section{Resumo}

Mundialmente, segundo o Global Report on Birth Defects, cerca de 7,9 milhões de bebês - 6\% do total de nascimentos - possuem ao nascimento alguma malformação congênita de origem genética ou parcialmente genética, enquanto outras centenas de milhares nascem com malformações congênitas desenvolvidas por causas evitáveis. A prevalência das causas de malformações não-genéticas é estipulada em torno de 5 a $10 \%$, principalmente, associadas à exposição materna a agentes teratogênicos, como medicamentos, álcool, tabaco, drogas ilícitas, micro-organismos, radiação, poluição ambiental, entre outros. Desta forma objetivou-se nesse estudo identificar a influência de alguns dos principais agentes teratogênicos químicos e biológicos nas malformações congênitas, através de uma revisão narrativa de literatura.

Palavras-chave: Desenvolvimento fetal; Saúde materno-infantil; Teratologia.

\section{Abstract}

Worldwide, according to the Global Report on Congenital Defects, about 7.9 million babies - 6\% of all births - have at birth some congenital malformation of genetic or partially genetic origin, while hundreds more are born with developed congenital malformations, preventable causes. The estimated value of the causes of non-genetic malformations is estimated at around 5 to $10 \%$, mainly associated with maternal exposure to teratogenic agents, such as medication, alcohol, tobacco, illicit drugs, microorganisms, radiation, environmental pollution, among others. Thus, this study aimed to identify the influence of some of the main chemical and biological teratogenic agents on congenital malformations, through a narrative literature review.

Keywords: Fetal development; Maternal and child health; Teratology.

\section{Resumen}

En todo el mundo, según el Informe mundial sobre defectos de nacimiento, alrededor de 7,9 millones de bebés (el 6\% de todos los nacimientos) tienen al nacer alguna malformación congénita de origen genético o parcialmente genético, mientras que cientos de miles más nacen con defectos de nacimiento desarrollados, debido a causas prevenibles. El valor estimado de las causas de malformaciones no genéticas se estima en alrededor del 5 al 10\%, principalmente asociadas a la exposición materna a agentes teratogénicos, como medicamentos, alcohol, tabaco, drogas ilícitas, microorganismos, radiaciones, contaminación ambiental, entre otros. Así, este estudio tuvo como objetivo identificar la influencia de algunos de los principales agentes teratogénicos químicos y biológicos sobre las malformaciones congénitas, a través de una revisión narrativa de la literatura.

Palabras clave: Desarrollo fetal; Salud maternal e infantil; Teratología. 


\section{Introdução}

A mortalidade infantil é caracterizada como um importante indicador da qualidade das ações e serviços de saúde de um país, por refletir as condições socioeconômicas, práticas de saúde pública e a saúde da mulher. Nos últimos 19 anos, os índices registraram uma queda de 56,1\% nas mortes de recém-nascidos e 59,8\% para crianças de até cinco anos. Entre as causas de mortalidade infantil, observa-se, uma diminuição nas taxas de óbitos por causas infecciosas, entretanto, precebe-se um aumento no índice de mortes decorrentes de malformações congênitas devido a agentes teratogênicos (Moreira, Neto \& Sucena, 2017).

Segundo o Global Report on Birth Defects, mundialmente, por ano, cerca de 7,9 milhões de bebês - 6\% do total de nascimentos - possuem ao nascimento alguma malformação congênita de origem genética ou parcialmente genética, enquanto outras centenas de milhares nascem com malformações congênitas desenvolvidas, por causas evitáveis. Estima-se que cerca de 5 a 10\%, destas, são malformações não-genéticas, principalmente, associadas à exposição materna a agentes teratogênicos, como medicamentos, álcool, tabaco, drogas ilícitas, micro-organismos, radiação, poluição ambiental, entre outros (Christianson, Howson \& Modell, 2006).

Países em desenvolvimento, como o Brasil, apresentam características que potencializam a ocorrência de danos na gestação por agentes teratogênicos. Entre estas características, destacam-se a dificuldade de acesso aos serviços de saúde, a venda irrestrita de medicamentos em farmácias e o consumo de substâncias proibidas durante o período gestacional (Faccini, 2002).

A Teratologia é um ramo da ciência médica que estuda a influência de agentes teratogênicos no desenvolvimento prénatal. Define-se agente teratogênico como qualquer substância, organismo, agente físico ou estado de deficiência que durante a gravidez pode interferir no desenvolvimento embrionário causando danos físicos ou mentais. Um agente ou condição, incluindo vírus, fármacos e produtos químicos, que pode comprometer o desenvolvimento pré-natal e resultar em defeitos ao nascer ou até mesmo em morte (Faccini, 2002).

Os agentes teratógenos agem por meio de mecanismos patogênicos que afetam o desenvolvimento fetal, atingindo mais de um tecido ou órgão, ocasionando em morte celular, alterações no crescimento dos tecidos (hiperplasia, hipoplasia ou crescimento assincrônico), interferência na diferenciação celular ou em outros processos morfogenéticos (Kalter \& Warkany, 1983).

As manifestações das ações de agentes teratogênicos na espécie humana são divididas em 4 classes: (1) morte do concepto ou infertilidade; (2) malformações; (3) retardo de crescimento intrauterino; e (4) deficiências funcionais. Estima-se que cerca de $15 \%$ de todas as gestações terminem em aborto e que 3\% de todos os recém-nascidos vivos apresentem algum defeito congênito (Kalter \& Warkany, 1983).

Com o intuito de contribuir com pesquisas que apontem os danos ao desenvolvimento fetal, decorrentes da ação de agentes teratogênicos, este estudo objetiva identificar a influência de agentes teratogênicos químicos e biológicos nas malformações congênitas.

\section{Metodologia}

Trata-se de uma pesquisa de revisão de literatura narrativa. Este tipo de estudo é utilizado como uma análise bibliográfica ampla, não sendo necessário determinar-se uma metodologia (Vosgerau \& Romanowsk, 2014). Entretanto, considera-se um método importante para a obtenção de um panorama geral do conhecimento acerca de um determinado tema, capaz de contribuir com a apresentação e discussão de novas evidências (Elias et al., 2012).

A busca da literatura ocorreu de dezembro de 2020 a fevereiro de 2021, sendo encontrados inicialmente 59 artigos, 
utilizando os descritores: "teratology" e "fetal development" e o operador booleano "AND" para a associação entre estes. O levantamento foi realizado no Portal Regional da Biblioteca Virtual em saúde, considerando as bases de dados: Literatura Latino Americana e do Caribe em ciências da Saúde (LILACS) e Medical Literature Analysis and Retrieval System Online (MEDLINE).

Para a seleção dos estudos, utilizou-se os seguintes critérios de inclusão: artigos originais, nos idiomas inglês ou português, não houve delimitação de período publicação devido à escassez de estudos recentes. Os critérios de exclusão foram: artigos duplicados, indisponíveis na íntegra e que não abordassem a temática. Assim, ao final, foram selecionados 43 artigos para análise e discussão.

\section{Resultados e Discussão}

\subsection{Desenvolvimento fetal}

Após a fecundação, um processo pelo qual o gameta masculino se une ao gameta feminino, há a formação do zigoto, uma célula diploide. $\mathrm{O}$ zigoto começa a passar pelo processo de clivagem, divisões mitóticas, sem aumento do volume celular que dão origem às células chamadas blastômeros, dando início ao desenvolvimento embrionário. O primeiro estágio da clivagem é a mórula, em que o embrião tem 16 células, e o segundo estágio é blástula, no qual o embrião, chamado de blastocisto, é formado por 32 células e ocorre a implantação no epitélio uterino (Gallahue, Ozmun \& Goodway, 2013).

A partir da blástula, inicia a fase de gástrula, onde há o aumento da massa do embrião, o surgimento do intestino primitivo e a diferenciação dos folhetos embrionários, os quais são ectoderme, endoderme e mesoderme. A última fase do desenvolvimento embrionário é a organogênese, caracterizada pela diferenciação dos tecidos e órgãos. O primeiro estágio da organogênese é a neurulação, onde ocorre a formação do tubo neural que posteriormente se diferenciará no sistema nervoso central. A organogênese termina até a oitava semana de gestação. Nesse período, o embrião mede cerca de 3 centímetros de comprimento. Depois da nona semana até o nascimento, o indivíduo em formação passa a ser chamado de feto (Berguer, 2017).

No final do segundo mês o feto mede cerca de 2 centímetros e pesa aproximadamente 9 gramas. Neste período a cabeça do feto tem o tamanho desproporcional para o comprimento do corpo, existem saliências para os dentes e língua e estão formados braços e pernas. As células ósseas aparecem aproximadamente na oitava semana. Os órgãos sexuais estão se desenvolvendo e as batidas cardíacas são regulares (Diane, Duskin \& Martorell, 2013).

No terceiro mês ocorre a diferenciação sexual, surge saliência para o estômago, os rins começam a funcionar, ao final do terceiro mês de gestação o feto tem cerca de 8 centímetros. No quarto mês ocorre um maior ritmo de crescimento, o feto dobra de tamanho, o esqueleto transparente e cartilaginoso transforma-se aos poucos em tecido ósseo e os membros inferiores alinham-se com o corpo (Gallahue, Ozmun \& Goodway, 2013).

No quinto mês, o feto atinge 50\% do seu comprimento ao nascer, entretanto tem apenas $10 \%$ do seu peso ao nascer. Neste período os órgãos internos continuam a crescer e ocupam suas posições anatômicas, no final do quinto mês, o feto mede cerca de 20 a 26 centímetros e pesa 227 gramas. No sexto mês, o feto apresenta uma pele vermelha e enrugada, está estruturalmente formado, entretanto ainda é imaturo, mede cerca de 36 centímetros e pesa 900 gramas (Berguer, 2017).

A partir do sétimo mês até o nascimento o feto tem seu peso triplicado, há a formação de uma camada de tecido adiposo sob a pele e o cérebro fetal torna-se mais ativo, controlando os sistemas corporais. No oitavo e nono mês o feto continua ganhando peso, ocorre a mudança de posição, seus movimentos ficam mais evidentes e a coloração vermelha diminui conforme os depósitos de gordura se distribuem. O feto pesa entre 3000 a 4000 gramas e mede, aproximadamente 50 centímetros (Diane, Duskin \& Martorell, 2013). 
Segundo Brown (2016), embora a gestação envolva um processo contínuo, ela pode ser dividida em três períodos de três meses, chamados de trimestres (semanas 0 a 12, 13 a 24 e 25 ao parto), conforme está representado no Quadro 1, adaptado do trabalho de Andrade (2019).

Quadro 1. Acontecimentos ocorridos durante o desenvolvimento fetal.

\begin{tabular}{|c|c|c|c|c|c|}
\hline Semana & Acontecimentos & Semana & Acontecimentos & Semana & Acontecimentos \\
\hline 0 & $\begin{array}{l}\text { Ocorre a última } \\
\text { menstruação da } \\
\text { mulher antes da } \\
\text { fertilização. }\end{array}$ & $14^{\mathrm{a}}$ & $\begin{array}{l}\text { Pode-se identificar o sexo do } \\
\text { feto. O feto consegue ouvir. }\end{array}$ & $25^{\mathrm{a}}$ & $\begin{array}{l}\text { O feto está ativo e } \\
\text { muda de posição } \\
\text { frequentemente. }\end{array}$ \\
\hline $2^{a}$ & $\begin{array}{l}\text { A fertilização ocorre. } \\
\text { O óvulo fertilizado } \\
\text { (zigoto). Formação } \\
\text { do blastocisto, uma } \\
\text { esfera oca de células. }\end{array}$ & $16^{\mathrm{a}}$ & $\begin{array}{l}\text { Os dedos do feto conseguem } \\
\text { segurar. O feto se move } \\
\text { vigorosamente e a mãe pode } \\
\text { senti-lo. O corpo do feto } \\
\text { começa a ganhar peso } \\
\text { conforme a gordura se deposita } \\
\text { sob a pele. Surge a pelugem. }\end{array}$ & $25^{\mathrm{a}}$ & $\begin{array}{c}\text { Os pulmões continuam } \\
\text { a amadurecer. }\end{array}$ \\
\hline $3^{a}$ & $\begin{array}{c}\text { O blastocisto se } \\
\text { implanta na parede } \\
\text { do útero. Inicia-se a } \\
\text { formação da bolsa } \\
\text { amniótica. }\end{array}$ & $20^{a}$ & $\begin{array}{c}\text { A placenta está totalmente } \\
\text { formada. }\end{array}$ & $25^{\mathrm{a}}$ & $\begin{array}{l}\text { A cabeça do feto se } \\
\text { move para a posição } \\
\text { do parto. }\end{array}$ \\
\hline $5^{\mathrm{a}}$ & $\begin{array}{l}\text { Inicia-se a formação } \\
\text { da área que se } \\
\text { tornará o cérebro e a } \\
\text { medula espinhal } \\
\text { (tubo neural). }\end{array}$ & $24^{\mathrm{a}}$ & $\begin{array}{c}\text { O feto tem chance de } \\
\text { sobreviver fora do útero. A } \\
\text { mulher começa a ganhar peso } \\
\text { mais rapidamente. }\end{array}$ & $25^{\mathrm{a}}$ & $\begin{array}{l}\text { Em média, o feto tem } \\
50 \mathrm{~cm} \text { de comprimento } \\
\text { e pesa aprox. } 3 \mathrm{Kg} \text {. O } \\
\text { abdômen aumentado } \\
\text { da mulher faz o } \\
\text { umbigo saltar. }\end{array}$ \\
\hline
\end{tabular}

Fonte: Readaptado pelos autores, conforme referência (Andrade, 2019 APUD Brown 2016).

\subsection{Fatores teratogênicos e sua influência nas malformações}

A partir do final do século 20, despertou-se uma preocupação com relação às possíveis substâncias utilizadas no período gestacional e seus impactos no embrião ou feto em desenvolvimento, uma vez que a utilização de medicamentos durante a gestação é algo, por vezes, necessária. A tragédia ocorrida pela utilização da talidomida ( $\alpha$-Nphthalimidoglutarimida) durante a gestação, no início da década de 1960, trouxe grande temor à população e aos médicos (Faccini, 2002). A talidomida possui importantes propriedades terapêuticas para um elevado número de doenças, contudo, no Brasil, recebeu aprovação para o tratamento de poucas condições clínicas, como o eritema nodoso da hanseníase (Mendes et al., 2018).

Vários estudos contam a história da talidomida em cada uma de suas etapas (Oliveira, Bermudez \& Souza (1999), Borges \& Froehlich (2003), Moos et al. (2003), Rajkumar (2004), Teo, Stirling \& Zeldis (2005). Resumidamente, os autores 
apontam que os estudos preliminares em humanos começaram tomando por base um único experimento que mostrou o efeito sedativo hipnótico da talidomida em camundongos, entretanto não havia nenhum outro estudo de toxicologia animal. Na época admitia-se também a ideia de que a intoxicação pela utilização da talidomida seria, praticamente, impossível. Assim, em 1957, ao generalizar, equivocadamente, os resultados incipientes encontrados em animais para os seres humanos, a farmacêutica Grunenthal lançou a talidomida no mercado (Oliveira, Bermudez \& Souza, 1999).

A empresa propusera várias indicações terapêuticas para a talidomida, tais como: baixa concentração, irritabilidade, estado de pânico, tensão pré-menstrual, ejaculação precoce, desordens funcionais do estômago e vesícula biliar, depressão leve, ansiedade, hipertireoidismo, doenças infeccionais febris e tuberculose. Embora não tivessem sido realizados estudos específicos sobre sua toxicidade reprodutiva que, inclusive, não eram obrigatórios nesse momento, a talidomida chegou a ser indicada como o melhor medicamento antiemético para ser utilizado por gestantes e lactantes (Franks, Macpherson \& Figg, 2004).

Durante a campanha publicitária, a empresa utilizou o slogan "Completamente atóxico, completamente seguro". Após a campanha, as vendas da talidomida aumentaram significativamente. Mundialmente, aproximadamente vinte países receberam licença para produzir e/ou distribuir a droga (Rajkumar, 2004). Em alguns países da Europa e no Canadá, podia ser adquirida sem receita médica. Contudo, nos Estados Unidos seu uso clínico não recebeu aprovação pelo FDA (Food and Drug Administration), devido a casos relatados de dormência nas mãos e pés de pessoas que a usavam por longo período, e ao incipiente conhecimento sobre o seu metabolismo (Berwanger, Costa \& Peres, 2001; Moos et al., 2003).

No fim da década 50 (1959), começaram a surgir relatos médicos acerca do aumento da incidência de nascimentos de crianças com um tipo peculiar de malformação congênita, cuja principal característica era o desenvolvimento defeituoso dos ossos longos dos membros. Essa malformação foi chamada de focomelia devido a semelhança com as nadadeiras das focas (Oliveira, Bermudez \& Souza, 1999).

Posteriormente outras malformações também foram observadas, como: defeitos na face e palato, ausência de orelhas, surdez e malformações do trato gastrointestinal. Pouco tempo depois, no início da década de 60 (1961), a talidomida foi retirada do mercado (Berwanger, Costa \& Peres, 2001; Politi, 2000).

No total, contabilizou-se o quantitativo de cerca de 12.000 recém-nascidos com malformações congênitas associadas ao uso da talidomida (Fernández-Camacho \& Leondorantes, 2000; Moos et al., 2003) em cerca de 46 países, incluindo o Brasil (Borges \& Fröehlich, 2003). Tais malformações em decorrência do uso da talidomida ocorrem quando a droga é ingerida por gestantes entre 35 a 49 dias após o último período menstrual (Berwanger, Costa \& Peres, 2001).

O álcool é outra substância capaz de ocasionar malformações congênitas, se consumida durante a gravidez. Entre as possíveis sequelas geradas pelo consumo desta substância, estão a Síndrome Alcoólica Fetal (SAF), os defeitos congênitos relacionados ao álcool e as desordens de neurodesenvolvimento relacionadas ao álcool (Bucher, 2015).

A SAF gera um quadro clínico mais grave, cujas manifestações são determinadas por um grupo de sinais e sintomas que variam de acordo com a quantidade de álcool consumida, o período gestacional, entre outros fatores. A SAF pode resultar em restrição do crescimento intrauterino e pós-natal, microcefalia, disfunções do sistema nervoso central e alterações faciais características, afetando em média $33 \%$ das crianças nascidas de mães que fizeram uso de mais de $150 \mathrm{~g}$ de etanol por dia (Santos, Estefanio \& Figueiredo, 2017).

As malformações ocasionadas pela SAF que foram descritas na literatura são: Craniofaciais - diminuição de olhos e pálpebras, (Barreto, 2007; Mesquita, 2010) estrabismo, ptose (Mesquita, 2010) dobras epicânticas, microftalmia, miopia e blefarofimose; Orelhas - pavilhão malformado, (Silva, 2002; Mesquita, 2010) Nariz - arrebitado, encurtado e hipoplásico; Boca - lábio leporino, fenda palatina lateral, lábio superior fino, maxilar achatado e dentes pequenos com esmalte imperfeito; 
Sistema Nervoso Central - microcefalia, disfunção com retardo mental leve ou moderado, coordenação falha, irritabilidade, hipotonia e hiperatividade na infância (Costa, 2001).

Em um estudo de coorte conduzido na cidade de Ribeirão Preto (SP), no ano de 2016, verificou-se que cerca de $23 \%$ das gestantes consumiram álcool durante a gravidez, e que a maior parte do consumo se deu durante o primeiro trimestre (14,8\%) (Sbrana et al., 2016). Os danos para o feto são diferentes, de acordo com o período gestacional (Barreto, 2007): no primeiro trimestre da gestação, o risco é maior para o desenvolvimento de anomalias físicas e dimorfismo; no segundo, há risco aumentado para abortamento; e, no terceiro, pode ocorrer diminuição do crescimento fetal, especialmente do perímetro cefálico e do cérebro (Mesquita, 2010; Veloso, 2013; Bucher, 2015).

Segundo Sbrana et al. (2016), o efeito da combinação entre o tabagismo e o álcool deve ser levado em consideração quando se aconselha mulheres sobre o comportamento saudável antes e durante a gravidez. No Brasil, o número estimado de mulheres grávidas que fumam é de 9,14\% havendo um considerável risco para ela e para a saúde do feto (Sbrana et al., 2016). Estudos apontam que a placenta de grávidas que fazem uso do tabaco apresenta hipoperfusão e como decorrência, retardo no crescimento intrauterino, pode ocorrer ruptura prematura da placenta (Leopércio, 2004; Gondim, 2006; Viggiano, 2007) e rotura prematura das membranas ovulares (Yamaguchi, 2008).

Yamaguchi (2008) relata que o hábito de fumar no período gestacional prejudica a saúde do recém-nascido, e também pode afetar a produção do leite materno (Gondim, 2006; Freire, 2009; Machado, 2009). O tabagismo está associado a problemas como: maiores taxas de aborto espontâneo, pré-eclâmpsia, retardo no crescimento fetal, redução do peso ao nascer, avanço da mortalidade infantil, prematuridade, anomalias congênitas e placentárias (Bastos, 2009; Machado, 2009; Freire, 2009; Rezende, 2012; Portela, 2013).

Não obstante, segundo Bastos (2009) os filhos de mães que usaram tabaco durante o período gestacional, possuem o risco de desenvolver um quadro denominado Transtorno do déficit de atenção com hiperatividade (TDAH) (Bastos, 2009; Brennan, 2012).

O North American Food and Drug A Administração (FDA) coleta o máximo de informações possíveis acerca de cada produto químico utilizado como medicamento, para endossar ou proibir seu uso em humanos. A depender do risco de teratogenicidade de cada um, atribui uma categoria denominada pelas letras: A, B, C, D ou X, embora esta classificação não leve em consideração uma análise individual dos medicamentos usados durante gravidez, continua a ser utilizada, pois poucos estudos adotam outras classificações de risco, impedindo a comparabilidade (Costa et al., 2020).

Tipo A: Estudos com essas drogas indicam um uso seguro. Tipo B: drogas inofensivas para animais, mas nenhuma pesquisa em humanos. Tipo C: Efeito positivo em animais, mas nenhuma pesquisa em seres humanos. Tipo D: Associado a efeitos adversos em humanos, mas o uso implica mais benefícios do que riscos. Tipo X: Estudos em humanos confirmam que os riscos de anormalidades superam os benefícios. Neste caso, a utilização da droga é definitivamente contra-indicada (Domínguez \& Núñez, 2014).

Desta forma, pode-se citar alguns medicamentos com potencial teratogênico, como os anticonvulsivantes fenitoína, ácido valpróico e trimetadiona, que são utilizados por mulheres epilépticas e podem provocar um amplo espectro de anormalidades que compõem diferentes padrões de dismorfogênese, conhecidas como síndromes de trimetadiona e hidantoína fetal. As fissuras faciais são comuns nessas síndromes (Sandler, 2013). O ácido valpróico pode causar anormalidades importantes, tais como: anormalidades cardíacas, cranianas e ósseas, defeitos de fechamento do tubo neural, e características dismórficas, bem como atraso do desenvolvimento cognitivo com manifestações de inteligência verbal diminuída com problemas de comunicação (Arancibia et al., 2015; Valdés, 2016).

Embora o feto ou o embrião esteja protegido pela placenta, alguns agentes infecciosos presentes na mãe podem atingilo por meio da circulação sanguínea. Os defeitos induzidos por micro-organismos nem sempre ocorrem no período da 
gestação, uma vez que muitas manifestações clínicas, mesmo que congenitamente adquiridas, podem surgir após o nascimento (Silva et al., 2011).

Costa et al. (2013) definem a transmissão vertical como aquela ocorrida entre a mãe (gestante/lactante) e seu filho, podendo acontecer pelas vias, como a ascendente (através do canal cervical), a hematogênica (através do aporte sanguíneo placentário) e o aleitamento materno. As infecções verticais por via hematogênicas são resultado da presença de diferentes agentes na circulação placentária, tais como bactérias (sífilis), protozoários (toxoplasmose) e vírus, como a rubéola (Costa et al., 2013).

A rubéola é uma doença infecciosa que produz sintomas leves e erupção generalizada. Causada por um vírus pertencente à família Togaviridae e ao gênero Rubivirus, possui simetria icosaédrica, é um vírus envelopado, com RNA de fita simples com polaridade positiva. A transmissão acontece por via aérea, e após a entrada no hospedeiro, pode ocorrer disseminação para diversos órgãos, incluindo a placenta. A rubéola congênita possui um efeito teratogênico, uma vez ao atingir a placenta, o vírus atinge o feto, inibe a mitose e estimula o aumento da apoptose celular, comprometendo assim a organogênese, sendo pior durante o primeiro trimestre da gestação. As principais manifestações relacionadas à infecção por Rubéola são: surdez, retardo mental, microcefalia, cataratas, glaucoma, retinopatia, cardiopatias, distúrbios motores, entre outros (Costa et al., 2013).

Causada pelo protozoário Toxoplasma gondii, a toxoplasmose é uma doença que pode ser adquirida por meio da ingestão de oocistos liberados pelas fezes de felídeos infectados, que podem estar presentes na água ou alimentos, ingestão de carne crua ou mal cozida, contendo cistos teciduais ou ainda, a transmissão de taquizoítos por via transplacentária. Neste caso, o parasito atravessa a barreira placentária, atinge o feto, gerando infecção congênita que pode resultar em complicações neurológicas, auditivas, oculares e morte intrauterina (Sartori et al., 2011).

$\mathrm{O}$ citomegalovírus (CMV) é um tipo de herpesvírus humano que pertence à família Herpesviridae. Possui simetria icosaédrica, envelope e seu genoma é formado por DNA. A infecção congênita pode ocorrer de três formas: transmissão vertical no período gravídico (via transplacentária), no momento do parto ou no período pós-natal (via leite materno). O CMV é capaz de infectar o feto tanto durante a infecção primária materna, quanto durante uma reativação da infecção materna presente antes da concepção. A infecção congênita por CMV pode ocasionar em: retardo do crescimento intra-uterino, prematuridade, icterícia colestática, plaquetopenia, hepato-esplenomegalia, púrpura, pneumonite intersticial, além de manifestações neurológicas como microcefalia, calcificações intracranianas, crises convulsivas no período neonatal, coriorretinite e deficiência de acuidade visual e auditiva. Destes, a surdez neurossensorial é a sequela mais frequente, atingindo cerca de $57 \%$ dos lactentes infectados (Junqueira, Sancho \& Santos, 2008).

A sífilis é uma infecção causada pela bactéria Treponema pallidum. Durante a gestação, pode causar sérias complicações para a mulher e seu concepto, podendo causar o abortamento, a morte intrauterina, o óbito neonatal ou deixar graves sequelas nos recém-nascidos. A transmissão vertical pode ocorrer, por via transplacentária, durante o momento do parto ou da amamentação, se o recém-nascido (RN) for exposto ao contato com lesões maternas (Silva et al., 2020).

Ressalta-se que não havendo diagnóstico e tratamento adequado da gestante infectada, a transmissão pode ocorrer em qualquer período da gestação independente do estágio da doença. Todavia, estudos apontam que há uma maior chance de contágio durante a fase recente da infecção, ou seja, nas fases primária e secundária da doença. Havendo o diagnóstico precoce e o tratamento adequado, o risco de transmissão é reduzido para 1 a $2 \%$ (Brasil, 2006).

A doença pode receber duas classificações de acordo com o tempo de diagnóstico. A sífilis congênita precoce que ocorre quando o diagnóstico é realizado até 2 anos de idade e o curso da doença se assemelha a sífilis secundária (Brasil, 2019). A criança pode apresentar erupções em forma de bolhas nas palmas, solas dos pés e ao redor da boca e nariz, hepatoesplenomegalia e fibrose hepática difusa, icterícia, anemia hemolítica, osteocondrite dolorosa e periostite. Pode ocorrer, 
ainda que de forma tardia, a deformidade característica do "nariz em sela", em decorrência da destruição do osso vômer (Kumar, 2010).

Na sífilis congênita classificada como tardia, os sinais e sintomas da doença surgem após o $2^{\circ}$ ano de vida, as manifestações clínicas mais importantes são: ceratite intersticial, tíbia em "Lâmina de Sabre", articulações de Clutton, fronte "olímpica", "nariz em sela", surdez do oitavo par craniano, molares em "amora", dentes de Hutchinson (dentes incisivos medianos superiores deformados), mandíbula curta, arco palatino elevado (Brasil, 2019)

Desde o ano de 2015, o vírus Zika, que é um arbovírus de RNA, teve sua circulação confirmada em pelo menos 18 estados brasileiros. Nesse período, observou-se um crescimento do número de nascidos vivos (NV) com microcefalia, esta malformação ocorre devido a uma lesão neuronal que interfere no desenvolvimento do cérebro, havendo redução do perímetro cefálico (Vargas et al., 2016).

Durante o intervalo entre 2000 e 2014 o número de casos de NV com microcefalia era estável. Marinho et al. (2016) verificaram que o número de casos dessa anomalia congênita no ano da confirmação da circulação do vírus aumentou cerca de nove vezes em relação à média anual do país (Marinho et al., 2016).

\section{Conclusão}

Os agentes teratogênicos podem causar diversas anomalias congênitas e contribuem para o aumento da mortalidade infantil, esse fato enfatiza a importância do conhecimento de algumas de suas causas, especialmente as que são consideradas evitáveis. É fundamental ser mencionado o papel da prevenção e promoção à saúde, através de campanhas educativas e da ampliação do acesso aos serviços de pré-natal de qualidade.

Se faz necessário que sejam investidos mais esforços em estratégias que auxiliem e acompanhem as crianças portadoras de anomalias congênitas, e recomenda-se que mais estudos sejam realizados a fim de se conhecer bem os fatores teratogênicos e suas causas associadas, minimizando seus riscos e diminuindo suas incidências.

\section{Referências}

Barreto, L. G. G. \& Packer, M. P. (2007). Dependência química na gravidez.

Bastos, M. D. S. \& Macedo, R. M. G. (2008). Prevenção de malformações congênitas, IV Mostra Interna de Trabalhos de Iniciação Científica do Cesumar, Paraná.

Berger, K. S. (2017). O desenvolvimento da pessoa do nascimento à terceira idade. LTC, (9a ed.).

Berwanger, C. G., Costa, E. C. \& Peres, R. M. (2001). Talidomida e ácido retinóico. In: Sanseverino, M. T. V.; Spritzer, D. T. \& Schüler-Faccini, L. Manual de Teratogênese. Ed. da UFRS.

Borges, L. G. \& Fröehlich, P. E. (2003). Talidomida: novas perspectivas para utilização como antiinflamatório, imunossupressor e antiangiogênico. Revista da Associação Médica Brasileira, 49(1): 96-102.

Brasil. (2006). Ministério da Saúde. Secretaria de Vigilância em Saúde. Coordenação Nacional de DST e Aids. Manual de bolso controle das doenças sexualmente transmissíveis DST. Brasília (DF): Ministério da Saúde.

Brasil. (2019). Ministério da Saúde. Secretaria de Vigilância em Saúde Departamento de Doenças de Condições Crônicas e Infecções Sexualmente Transmissíveis. Protocolo clínico e diretrizes terapêuticas para atenção integral às pessoas com infecções sexualmente transmissíveis (ist). Brasília, 250p.

Brown, H. L. (2016). Gestação Normal. Manual MSD Versão Saúde para a Família. <https://www.msdmanuals.com/pt-br/casa/problemas-desa\%C3\%BAdefeminina/gesta\%C3\%A7\%C3\%A3o-normal/est\%C3\%A1gios-dodesenvolvimento-do-feto>

Bucher, B. (2015). Alcoolismo feminino e gestação: Prazer e deficiência andam juntos, Revista Conexão Eletrônica, 12(1):1-12.

Costa, D. B., Castro, C. T. de, Gama, R. S., \& Santos, D. B. dos. (2020). Uso de medicamentos segundo classificação de risco e fatores associados entre gestantes: resultados da coorte NISAMI. Research, Society and Development, 9(12), e43691211247.

Costa, F. A. Z., Quadrado, A. V. M., Brandão, A. P., Paes, L. B. A., Carneiro, B. V., Castanho, D. L. M. \& Rocha, C. H. R. (2013). Síndrome da Rubéola Congênita: revisão de literatura. Revista Medicina e Saúde, 1(2): 46-57. 
Costa, K.L.B. \& Tocci, H. A. (2001). O uso do álcool durante a gestação: possíveis problemas para a gestante e o feto. Revista de Enfermagem, 2:5-8.

Christianson, A., Howson, C. \& Modell, B. (2006). Global Report on Birth Defects: the hidden toll of dying and disabled children. White Plains.

Diane, E. P., Duskin, R. F. \& Martorell, G. (2013). Desenvolvimento Humano. AMGH, 12, ed.

Domínguez G. C. \& Núñez, A. I. B. (2014). Álcool, tabaco e malformações lábio-alveolares congênitas. MEDISAN, 18 (9): $1293-1297$.

Faccini, L. S., Leite, J. C. L., Sanseverino, M. T. V. S. \& Peres, R. M. (2002). Avaliação de teratógenos na população brasileira. Ciência \& Saúde Coletiva, 1(7): $65-71$.

Fernández-Camacho, Y. \& Leon-Dorantes, G. (2000). Talidomida: una nueva oportunidad. Revista Médica del Hospital General de México, 63(3): 185-191.

Franks, M. E., Macpherson, G. R. \& Figg, W. D. (2004). Thalidomide. Lancet, 263: 1802-1811.

Gallahue, D. L., Ozmun, J. C \& Goodway, J.D. (2013). Compreendendo o desenvolvimento m otor: bebês, crianças, adolescentes e adultos. AMGH, (7a. ed.).

Kalter, H. \& Warkany, J. (1983). Congenital malformations: etiological factors and their role in prevention (first of two parts). New England Journal of Medicine, 308: 424-431.

Kumar, V., Abbas, A. K., Fausto, N., Robbins \& Cotran. (2010). Patologia: Bases patológicas das doenças. (8th ed.), Elsevier, 1480p.

Marinho, F., Araújo, V. E. M., Porto, D. L., Ferreira, H. L., Coelho, M. R. S., Lecca, R. C. R., \& Neto, D. L. R. (2016). Microcefalia no Brasil: prevalência e caracterização dos casos a partir do Sistema de Informações sobre Nascidos Vivos (Sinasc), 2000- 2015. Epidemiologia e Serviços de Saúde, 25 (4):701-712.

Mendes, I. C., Jesuino, R. S. A., Pinheiro, D. S. \& Rebelo, A. C. S. (2018). Anomalias congênitas e suas principais causas evitáveis: uma revisão. Revista Médica de Minas Gerais, 28: e-1977.

Mesquita, M. D. A. (2010). Efeitos do álcool no recém-nascido, Einstein, 8(3):368- 375.

Moos, R. V., Stolz, R., Cerny, T. \& Gillessen, S. (2003). Thalidomide: from tragedy to promise. Swiss Medical Wkly, $133:$ 77-87.

Moreira, M. R., Neto, O. C. \& Sucena, L. F. M. (2017). Um olhar sobre condições de vida: mortalidade de crianças e adolescentes. Cadernos de Saúde Pública, 19(1):161-173.

Oliveira, M. A., Bermudez, J. A. Z. \& Souza, A. C. M. (1999). Talidomida no Brasil: vigilância com responsabilidade compartilhada? Cadernos de Saúde Pública, 15(1): 99-112.

Politi, P. M. (2000). Talidomida: Ensayos clinicos en cancer. Medicina, 60: 61-65.

Rajkumar, S. V. (2004). Thalidomide: Tragic past and promising future. Mayo Clinic Proceedings, 79(7): 899- 903.

Santos, R. S., Estefanio, M. P. \& Figueiredo, R. M. (2017). Prevenção da síndrome alcoólica fetal: subsídios para a prática de enfermeiras obstétricas. Revista de enfermagem UERJ, 25(1): 1-7.

Sartori, A. L., Minamisava, R., Avelino, M. M. \& Martins, C. A. (2011). Triagem pré-natal para toxoplasmose e fatores associados à soropositividade de gestantes em Goiânia, Goiás. Revista Brasileira de Ginecologia e Obstetrícia, 33(2): 93-98.

Sbrana, M., Grandi, C., Brazan, M., Junquera, N., Nascimento, M. S., Barbieri, M. A., Bettiol, H. \& Cardoso, V. C. (2016). Alcohol consumption during pregnancy and perinatal results: a cohort study. Medical Journal, 134 (2): 146-52.

Silva, A., Arancibia, M., Pulgar, C., Astorga, L., Castillo, A., \& Adasme, V. (2015). Exposição a agrotóxicos e práticas de u so e proteção em gestantes rurais no controle da atenção primária na região de Valparaíso, Chile. Revista Chilena de Obstetricia y Ginecología, 80 (5): 373 -380.

Silva, M. S., Santos, M. P., Silva, E. R. B., Oliveira, F. V., Havenstrin, V. C. L., Silva, T. K. C. \& Silva, W. K. L. B. (2020). Sífilis congênita: reflexões acerca de um agravo prevalente. In: Silva, W. M., Silva, M. E., Santos, M. P., Santos, J. A., Silva, E. R. B., Silva, T. K. C., Lima, J. M. G., Havenstrin, V. C. L., Oliveira, F.V., Souza J. N. V. A., \& Silva, W. K. L. B. (2020). Estudos em saúde pública uma análise crítica dos principais agravos de notificação compulsória. RFB Editora, 46p.

Silva, S. R. G., Martins, J. L., Seixas, S., Silva, D. C. G., Lemos, S. P. P. \& Lemos, P. V. B. (2011). Defeitos congênitos e exposição a agrotóxicos no Vale do São Francisco. Revista Brasileira de Ginecologia e Obstetrícia, 33(1): 20-6.

Silva, T. P. \& Tocci, H. A. (2002). Efeitos obstétricos, fetais e neonatais relacionados ao uso de drogas, álcool e tabaco du rante a gestação. Revista de Enfermagem, 3:50-6.

Teo, S. K., Stirling, D. I. \& Zeldis, J. B. (2005). Thalidomide as a novel therapeutic agent: new uses for an old product. Drug Discovery Today, 10(2): 107114.

Vargas, A., Saad, E., Dimech, G. S., Santos, R. H., Sivini, M. A. V. C., Albuquerque, L. C., \& Percio, J. (2016). Características dos primeiros casos de microcefalia possivelmente relacionados ao vírus Zika notificados na Região Metropolitana de Recife, Pernambuco. Epidemiologia e Serviços de Saúde, 25 (4): 691-700.

Veloso, L. U. P \& Monteiro, C. F. D. S. (2013). Prevalência e fatores associados ao uso de álcool em adolescentes grávidas, Revista Latino-Americana Enfermagem, 21(1):09. 